Volume 8. No. 9, September 2020

International Journal of Emerging Trends in Engineering Research

Available Online at http://www.warse.org/IJETER/static/pdf/file/ijeter66892020.pdf

https://doi.org/10.30534/ijeter/2020/66892020

\title{
Engineering Properties of Concrete Incorporating Locally Produced Waste Glass Aggregate
}

\author{
Bengin M. A. Herki \\ ${ }^{1}$ Department of Civil Engineering, College of Science and Engineering, Bayan University, Erbil, Kurdistan-Iraq \\ ${ }^{2}$ Department of Civil Engineering, Faculty of Engineering, Soran University, Erbil, Kurdistan-Iraq \\ bengin.awdel@bnu.edu.iq
}

\begin{abstract}
In recent years, with increasing environmental pressure to reuse, reduce or recycle as much wastes as possible cross the world, the concrete industry has implemented a number of recycling methods to achieve this goal. One of the oldest construction materials that have been utilised by human being in many projects for decades is glass. As a result a large volume of post-consumer glass is being generated by people and discarded on a regular basis which is likely to increase considerably in the future. Thus, many studies have been done to investigate different recycling techniques and the potential use of waste glass (WG) as aggregates in making concrete. For the present study, four concrete mixtures in total with varying crushed waste glass as a partial replacement for natural fine aggregate at $0 \%, 15 \%, 30 \%$ and $60 \%$ were prepared. The water/cement ratio of 0.5 was kept constant for all concrete mixtures. The properties investigated were aggregates particle size distribution, consistency, dry density, compressive strength and total water absorption of concrete containing varying amounts of WG. According to the results obtained with increasing WG content in concrete the compressive strength decreased compared with the control concrete. The minimum 28 days strength obtained at $60 \%$ WG. However, with appropriate mix design utilisation of WG in concrete production especially in low-strength applications is possible. However, before such concrete can be considered safe for general use in concrete, long-term concrete engineering tests need to be carried out.
\end{abstract}

Key words: Aggregate, Concrete, Durability, Waste glass.

\section{1- INTRODUCTION \& BACKGROUND}

According to the environmental studies conducted in recent years there has been a shift of trend towards using more environmentally friendly materials such as by-products, waste and recycled materials in making concrete which have shown to have related purposes, rather than using up the natural resources $[1,2]$. Therefore, waste and recycled materials in concrete as aggregate replacement will not only reduce the waste produced by people but also preserve the natural resources [3, 4]. One of the best environmental techniques is recycling of waste materials. In fact, utilisation of waste materials (i.e., by-products, plastics and glass etc.) in concrete production is one of the key research interests to reach the goal of achieving sustainability in construction industry. One of such waste materials is WG. A large quantity of glass is disposed in landfills or dumped in open spaces as a waste. For example, every year, about 850 million tons of construction wastes are produced in the European countries; this is about $30 \%$ of the total waste generated in these countries. United Nations estimates the volume of yearly disposed solid waste to be 200 million tons, $7 \%$ of which is made up of glass cross the world [5]. Although, there are no reliable data on the quantities of waste glass generated in Kurdistan-Iraq, unfortunately there is an obvious sign of a sharp increase in their accumulated quantities as discarded solid wastes due to the absence of or poorly functioning systems for the collection and disposal of these wastes. Collecting WG before disposed in open space areas or in landfill sites in crushed and graded form can be used as aggregates to use in concrete. Recent studies on WG concrete emphasise that as the amount of WG increases, so does the air content due to the awkward shape of the WG and poor compactness. Compressive, tensile and flexural strengths all decrease when adhesion is not fully achieved in the concrete containing WG. Coarse WG particles, used as aggregate, produced poor concrete strength, due to WG aggregates extremely poor shape, poor surface characteristics, and high friability [6,7]. As reported by the research [5] revealed that using WG as aggregate did not have a noticeable effect on the workability of concrete. As reported earlier when WG content in concrete increased the slump, air content and fresh density decreased. They also reported that with increasing WG in concrete compressive, flexural and tensile strengths' values decreased. Specifically, the compressive strength decreased almost 50\% with a $60 \%$ replacement level of WG. However, they concluded that replacing WG with natural fine aggregates better results can be obtained assuming that its geometry be more proper and almost sphere-shaped. The main aim of the present study is to set up an experimental programme to create a realistic approach in order to investigate the influence of WG 
Bengin M. A. Herki, International Journal of Emerging Trends in Engineering Research, 8(9), September 2020, $5302-5306$

based aggregates on the engineering properties of concrete and produce a sustainable material for construction industry in developing countries including Kurdistan-Iraq. The specific objectives of the present study are investigating physical, mechanical and durability properties of concrete incorporating different WG contents as locally produced aggregates at different curing periods.

\section{2- EXPERIMENTAL PROGRAMME 2.1 Materials}

All materials used in the present study are locally available. The Ordinary Portland Cement (OPC) (Table 1), natural fine aggregate (NFA) and natural coarse aggregate (NCA) $(10 \mathrm{~mm})$ was used in concrete mixes. For particle size distribution (sieving) (Figures 1,2) test, a representative sample of the aggregates was placed in the oven and dried to a constant weight at a temperature of $110{ }^{\circ} \mathrm{C}$ complied with BS EN 933-1:1997 [8]. The WG as a locally produced material to replace natural fine aggregate was also used in making concretes. The WG was collected from different areas of Soran town, Kurdistan, Iraq. The collected waste glass includes flat glass mainly used for windows.

Table 1: Chemical properties of cement currently available in Kurdistan-Iraq

\begin{tabular}{ll}
\hline Compounds & (\% by weight) \\
\hline $\mathrm{CaO}$ & 64.43 \\
$\mathrm{SiO}_{2}$ & 21.14 \\
$\mathrm{Al}_{2} \mathrm{O}_{3}$ & 5.78 \\
$\mathrm{Fe}_{2} \mathrm{O}_{3}$ & 3.59 \\
$\mathrm{SO}_{3}$ & 2.35 \\
$\mathrm{MgO}$ & 1.52 \\
$\mathrm{Loss}$ of ignition & 0.89 \\
Lime saturation factor & 0.92 \\
Insoluble residue & 0.34 \\
$\mathrm{Main}$ compounds (Bogue's equation) \% by weight \\
$\mathrm{C}_{3} \mathrm{~S}$ & 50.83 \\
$\mathrm{C}_{2} \mathrm{~S}$ & 22.30 \\
$\mathrm{C}_{3} \mathrm{~A}$ & 9.25 \\
$\mathrm{C}_{4} \mathrm{AF}$ & 10.90 \\
\hline
\end{tabular}

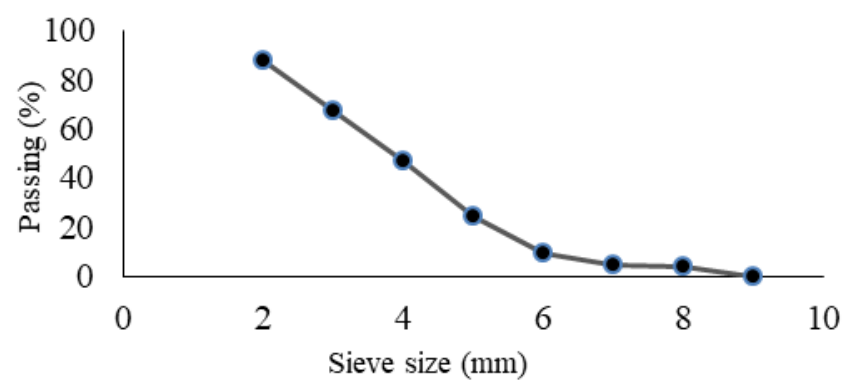

Figure 2: Particle size distribution of $\mathrm{WG}$

\subsection{Mix Proportions}

Four concrete mixtures in total were used for the present study. A comprehensive summary of the concrete details (ingredients) are presented in table 2 . In order to investigate the effect of the WG aggregate on physical, mechanical and durability properties of concrete, mixtures were prepared in different aggregate replacement levels.

The control mixture had a proportion of 1 (cement): 2 (natural fine aggregate): 4 (natural coarse aggregate). The replacement levels of natural fine aggregate by WG were $0,15,30$ and $60 \%$. The water to cement ratio (W/C) of 0.5 , amount of water, cement and natural coarse aggregate was kept constant for all mixtures. The mixing of materials was done in a specific arrangement, by placing a part of the water with adding the dry aggregates, which was thoroughly mixed for about 2 minutes to get the aggregates wetted with water. Then, the remaining materials were added to the container and the remaining water was gradually added while the mixing was in progress. The mixing was continued until a mix of uniform consistency was achieved. The slump values complied with BS EN 12350-2:2009 [9] was done immediately after mixing for all the concrete mixtures. Standard test specimens have already chosen for investigating the various properties. Specimens were cast in steel moulds. After casting, specimens were covered and left in the laboratory for 24 hours. Then, specimens were de-moulded and placed in water for different curing times. Mix preparation is very important when using sharp materials like WG and enough care was exercised during mixing, pouring and compacting processes.

Table 2: Actual details of concrete ingredients

\begin{tabular}{|c|c|c|c|c|c|c|}
\hline \multirow[t]{2}{*}{ Mix } & \multirow{2}{*}{$\begin{array}{l}\text { WG } \\
\text { replacemen } \\
\text { t }(\%)\end{array}$} & \multicolumn{2}{|c|}{$\begin{array}{l}\text { Fine agg. } \\
\text { (kg) }\end{array}$} & \multirow{2}{*}{$\begin{array}{l}\text { Coarse } \\
\text { agg. } \\
\text { (kg) }\end{array}$} & \multirow[t]{2}{*}{$\begin{array}{l}\text { Cement } \\
\text { (kg) }\end{array}$} & \multirow[t]{2}{*}{$\begin{array}{l}\text { Wate } \\
\mathbf{r}(\mathbf{k g})\end{array}$} \\
\hline & & $\begin{array}{l}\text { Natura } \\
1\end{array}$ & WG & & & \\
\hline 1 & 0 & 21.6 & 0.0 & 43.2 & 10.8 & 5.4 \\
\hline 2 & 15 & 18.4 & 3.2 & 43.2 & 10.8 & 5.4 \\
\hline 3 & 30 & 15.1 & 6.5 & 43.2 & 10.8 & 5.4 \\
\hline 4 & 60 & 8.6 & $\begin{array}{l}13 . \\
0\end{array}$ & 43.2 & 10.8 & 5.4 \\
\hline
\end{tabular}


Bengin M. A. Herki, International Journal of Emerging Trends in Engineering Research, 8(9), September 2020, $5302-5306$

\subsection{Specimen Preparation and Testing Procedure}

\subsubsection{Slump Measurement}

Slump test was carried out to measure the concrete consistency. This was done according to the specifications of BS EN 12350-2:2009 [9].

\subsubsection{Density}

Cubes of $150 \times 150 \times 150 \mathrm{~mm}$ size were used for the determination of dry density. The cubes were dried until a constant dry mass was attained complied with BS EN 12390-7:2009 [10]. The dry density test was carried out on three cubes for each concrete mix and the average was used for analysis purposes.

\subsubsection{Compressive Strength}

Cubes of $150 \times 150 \times 150 \mathrm{~mm}$ size were used for the determination of compressive strength at 7, 14 and 28 days. The specimens were under water curing until the day of testing. Compressive strength test was carried out using testing machine of $3000 \mathrm{KN}$ capacity at the loading rate of $0.6 \mathrm{MPa} / \mathrm{s}$ according to BS EN 12390-3:2009 [11]. Compressive strength test was carried out on three cubes from mix combination and the average was used for analysis purposes.

\subsubsection{Total Water Absorption (WA)}

Specimens of $150 \times 150 \times 150 \mathrm{~mm}$ size were used for total water absorption test at 28 days. The specimens were cured in normal temperature water until the day of testing. Saturated surface dry cubes were kept in a hot air oven at $110^{\circ} \mathrm{C}$ until a constant dry mass was attained. Specimens were immersed in water and the increase in weight was measured at regular intervals until a constant wet mass is attained. The final wet mass of specimens when the difference between two consecutive values after 12-hour interval is almost zero was recorded as total water absorption of concrete.

\section{TEST RESULTS \& DISCUSSION}

\subsection{Consistency}

The consistency or workability values for concretes containing varying amounts of WG aggregate are presented in Figure 3. Slump test measurements were carried out on all four mixtures. Slump test is one of the methods to measure the workability (consistency) of fresh concrete. The slump values were in the range of $12-16 \mathrm{~mm}$.

As it was reported earlier [5], using WG as aggregate did not have a noticeable effect on the consistency of concrete. However, and as can be seen in the slump values obtained the workability of the concrete slightly increased with the increase in WG content. This is because the WG particles do not absorb water and thin water layers can stick to the surfaces of WG particles.

\subsection{Fresh and Dry Density}

Figure 4 and 5 present fresh and dry density of concrete containing different amounts of WG. The fresh density of concretes containing different replacement levels of WG particles were between 2325 and $2415 \mathrm{~kg} / \mathrm{m}^{3}$ and dry density values were between 2330 and $2395 \mathrm{~kg} / \mathrm{m}^{3}$. Generally, there is a decrease in concrete density with increase in WG content. However, it is interesting to see that the density of the concretes decreased with the increase in WG up to $15 \%$ then slightly increased at 30\% and finally decreased at 60\% WG replacement. The decrease in density was $4 \%$ only for concrete containing $60 \% \mathrm{WG}$ compared to control. The reduction in the density of the concrete mixtures can be attributed to the specific gravity of the WG particles, which is about $15 \%$ less than that of the natural fine aggregate [12]. Despite reduction in the density of concrete made with WG, they are still comparable to the control mixtures. As we know, density of concrete depends upon the density, volume, moisture content and grading of the aggregates, mix proportions, cement content, water/binder ratio, chemical and mineral admixtures, method of compaction and curing conditions [13].

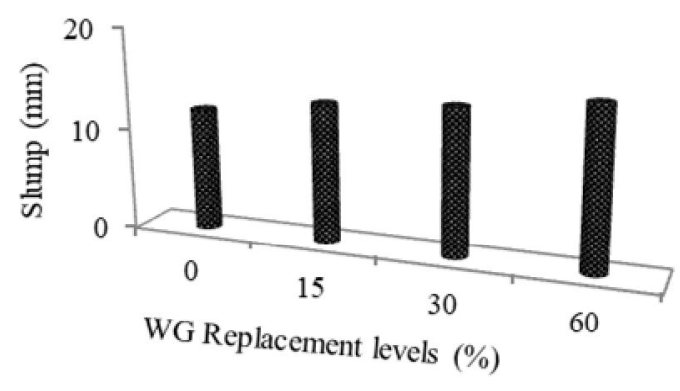

Figure 3: Slump values of concrete containing varying amounts of WG

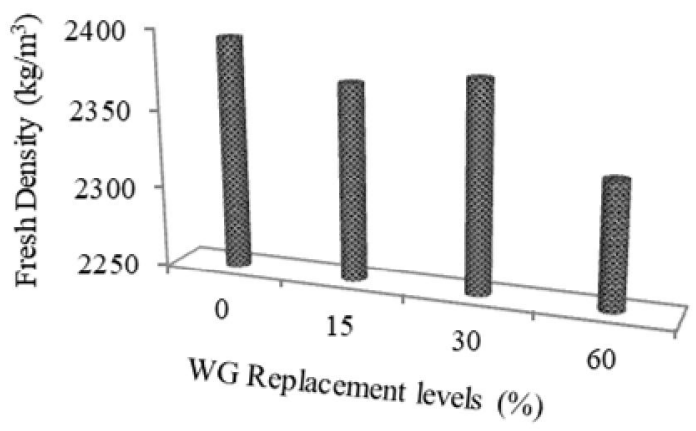

Figure 4: Fresh density of concrete containing WG 
Bengin M. A. Herki, International Journal of Emerging Trends in Engineering Research, 8(9), September 2020, $5302-5306$

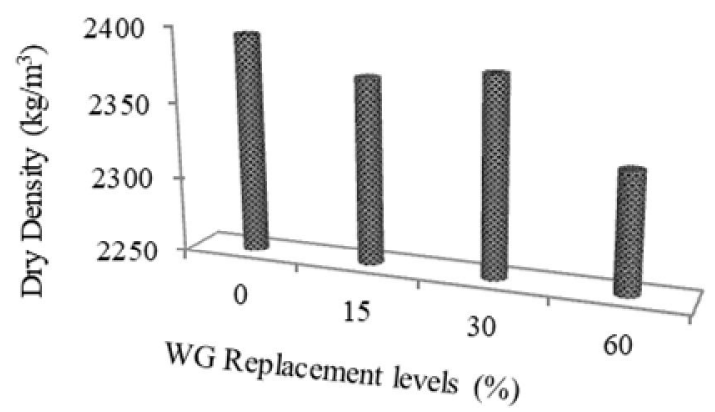

Figure 5: Dry density of concrete containing WG

\subsection{Compressive Strength}

Figure 6 shows compressive strength of concretes containing different amounts of WG aggregate at different curing times. At the curing age of 28 days the concretes' compressive strength were between 32 and $37 \mathrm{MPa}$. Due to the lower strength of WG particles than natural aggregates, the incorporation of WG caused a reduction in the concrete compressive strength. The reduction in compressive strength of the concretes was $2 \%, 8 \%$, and $13 \%$ for WG replacement levels of 15,30 and $60 \%$, respectively, in comparison with the control concrete of the same age. The main reason may be the unimodal size distribution of WG particles, as showed in Figure 2. This may result in significantly reduced compacting and larger volume of pores. As we know concrete with high pore volume would lead to a decrease in compressive strength. The low compressive strength of concrete containing WG could also be attributed to the decrease in the bond strength between the surface of the WG particles and the cement paste. According to the results obtained and as expected the compressive strength increases with curing periods for all concrete mixes. Control mix (0\% WG) gained $72 \%$ of 28 -day strength in the first 7 days of curing. This strength development for mixes $2(15 \% \mathrm{WG}), 3(30 \% \mathrm{WG})$ and $4(60 \% \mathrm{WG})$ is $73 \%$, $77 \%$ and $77 \%$, respectively. The strength development for concrete mixes slightly increasing with increase in WG content. According to the internationally recognized

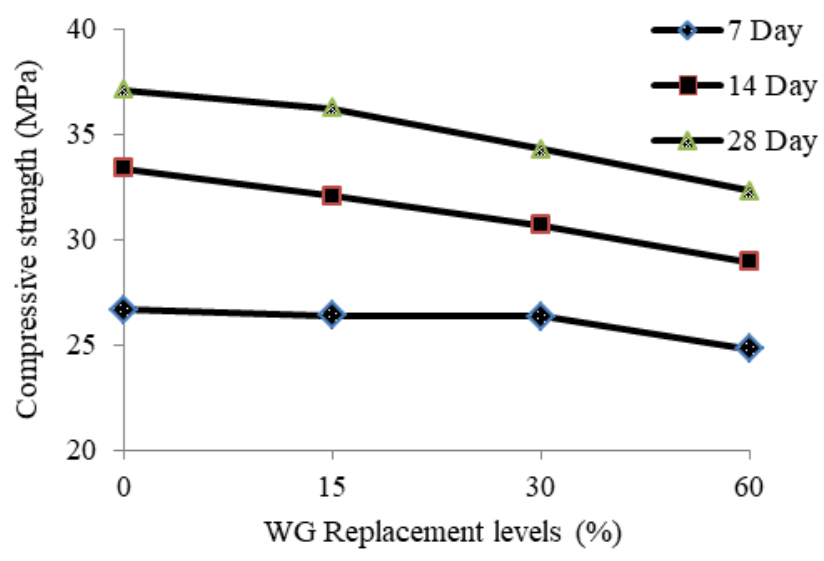

Figure 6: Compressive strength of concrete containing WG at different curing times standards, a minimum strength required for heavy duty bearing concrete blocks is $7.5 \mathrm{MPa}$ [14]. Therefore, all concrete mixtures made with different replacement levels of WG aggregate in the present study are suitable to make all types of blocks including heavy duty bearing concrete blocks. The concrete containing lower amounts of WG can comply with the necessary minimum requirements of structural concrete.

\subsection{Water Absorption}

Figure 7 presents water absorption (WA) of concrete containing different amounts of WG. The total water absorption of all concrete mixtures was about 5\% approximately at the 28 days age. An increase in water absorption is an indication of an increase in the volume of pores $[15,16]$. This may be due to the unimodal grain size distribution of WG, as presented in Table 2, may have led to less compacting and in result making high volume of pores. As reported earlier, larger pore volume would lead to a decrease in strength and an increase in water absorption.

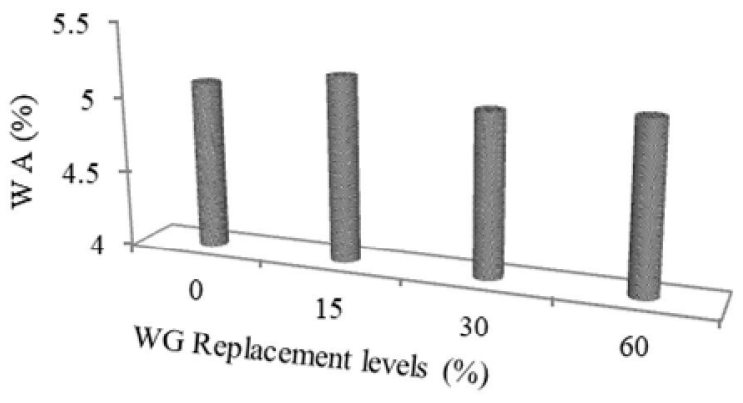

Figure 7: WA of concrete containing WG

\section{CONCLUSION}

Reusing and recycling of waste materials can be considered the best technique to solve the environmental problems of waste materials not only in Kurdistan Region-Iraq and developing countries but whole the world. According to the experimental results obtained the influence of an increase in WG content in concrete on workability and water absorption was not noticeable. Compressive strength and density of concrete decreased with increase in WG content. With appropriate mix design, the utilisation of WG in concrete production especially in low-strength applications such as in local road beds, pavement and parking lots, and producing heavy duty bearing concrete blocks is possible. The concrete containing lower amounts of WG can comply with the necessary minimum requirements of structural concrete. However, as the main recommendation for further possible work in the future, long-term mechanical and durability properties of the concrete need to be investigated before such concrete can be considered safe for general use in civil engineering applications. 
Bengin M. A. Herki, International Journal of Emerging Trends in Engineering Research, 8(9), September 2020, $5302-5306$

\section{REFERENCES}

1. A. Awad. Guidelines for Civil Structures Demolition Method Selection to Enhance Environmental Protection. International Journal of Emerging Trends in Engineering Research, 8(2), pp, 307 - 313. 2020.

2. F. Al Adday and F. Alsaleh. Study the Possibility of Using the Modified Asphalt Mixtures with Waste Plastic in High-Temperature Areas. International Journal of Emerging Trends in Engineering Research, 8(4), pp, 1090 - 1095. April 2020.

3. C. Meyer. Concrete and Sustainable Development, Special Publication, 2002, ACI 206.

4. A. Chegenizadeh, M. Keramatikerman, and H. Nikraz. Relative Density Effect on Shear Behaviour of Fibre-Fly ash-Sand. International Journal of Emerging Trends in Engineering Research, 8(4), pp 1259 - 1263, April 2020.

5. I.B. Topcu, and M. Canbaz. Properties of concrete containing waste glass. Cement and Concrete Research, 34 (2), pp, 267-274. 2004.

6. S.B. Park, B.C. Lee and J.H. Kim. Studies on Mechanical Properties of Concrete Containing Waste Glass Aggregate. Cement and Concrete Research. 34 (12) pp, 2181-2189, 2004.

7. C. Polley, S. M. Cramer and R. V. Cruz. Potential for using waste glass in Portland cement concrete, J. Mater. Civ. Eng. (10) pp, 210- 219, 1998.

8. BS EN 933-1:1997 Tests for geometrical properties of aggregates. Part 1: Determination of particle size distribution - Sieving method. 1997.

9. BS EN 12350-2:2009 Testing fresh concrete Part 2: Slump-test.2009.

10. BS EN 12390-7:2009 Testing hardened concrete Part 7: Density of hardened concrete. 2009.

11. BS EN 12390-3:2009 Testing hardened concrete Part 3: Compressive strength of test specimens. 2009.

12. Z. Ismail and E.Hashemi. Recycling of waste glass as a partial replacement for fine aggregate in concrete, Waste Management (29) pp, 655-659. 2009.

13. A. M. Neville and J. J. Brooks. Concrete technology, Longman scientific and technical. New York, NY: Long-man Publisher. 2004.

14. L. Gunduz. The effects of pumice aggregate/cement ratios on the low-strength concrete properties, Construction and Building Materials, 22(5), pp. 721-728. 2008.

15. B.A. Herki and J.M. Khatib. Valorisation of waste expanded polystyrene in concrete using a novel recycling technique, European Journal of Environmental and Civil Engineering, pp, 1-19, 2016.

16. J.M. Khatib and B.A. Herki. Capillarity of concrete incorporating waste foundry sand, Construction and Building Materials 47, pp, 867-871. 2013. 